\title{
Concentration ratios for chemical analogues of key nuclides for different vegetation types at the Olkiluoto site
}

\author{
L.J. Aro ${ }^{1}$, A.T.K. Ikonen ${ }^{2}$ and J. Helin ${ }^{2}$ \\ ${ }^{1}$ Finnish Forest Research Institute, Parkano Research Unit, \\ Kaironiementie 54, 39700 Parkano, Finland \\ ${ }^{2}$ Posiva Oy, Olkiluoto, 27160 Eurajoki, Finland
}

\begin{abstract}
Olkiluoto Island on the western coast of Finland has been selected as a repository site for spent nuclear fuel in Finland. This study aimed at identifying differences in concentration ratios (CR), and their distributions, for the elements analysed on soil and vegetation samples taken on the island ( $\mathrm{Al}, \mathrm{B}, \mathrm{Ca}$, $\mathrm{Cd}, \mathrm{Cr}, \mathrm{Cu}, \mathrm{Fe}, \mathrm{K}, \mathrm{Mg}, \mathrm{Mn}, \mathrm{Ni}, \mathrm{P}, \mathrm{S}, \mathrm{Zn}$ ). Many of the elements can be considered to be chemically analogous to radionuclides that, potentially, can be released from the repository. Differences between the soil and vegetation in different tree age, tree species and site fertility classes typical of the forest ecosystems in Olkiluoto were investigated. Lognormal distributions were fitted to the different groupings of the CR data calculated on the basis of the results from 94 sampling plots. In most cases no significant differences were found between the different groupings for a specific element when the $95 \%$ confidence intervals were applied. According to the results based on real site data for CRs in forest ecosystems on Olkiluoto, it appears that the current CR-based approach to radionuclide modelling in forest ecosystems is problematic due to the large variation in parameter values and in their practical definition.
\end{abstract}

\section{INTRODUCTION}

Olkiluoto Island on the western coast of Finland has been selected as a repository site for spent nuclear fuel in Finland. In order to monitor possible environmental changes during the construction and operation of the repository and to provide the radioecological models with site-specific empirical data, an extensive sampling programme on forest vegetation was implemented in 2005. The programme included surveys of vegetation and forest soil, and mapping of the nutrient status of the vegetation on Olkiluoto.

The concentration ratio is defined as the ratio of the specific radionuclide activity in the plant tissue of interest and the corresponding activity in the soil. The ratios can also be calculated for the stable isotopes of elements, such as potassium $(\mathrm{K})$ and calcium $(\mathrm{Ca})$, which are essential macronutrients for plants. In such cases the concentration ratio is merely the ratio of the respective concentrations.

This study aimed at identifying differences in the concentration ratios and their distributions of the elements for which chemical analysis data are now available. Many of the elements can be considered to be chemically analogous to the radionuclides that, potentially, can be released from the repository in the Olkiluoto site. In general, $\mathrm{K}$ has been used as an analogue for caesium (Cs), and $\mathrm{Ca}$ for strontium ( $\mathrm{Sr}$ ) and radium ( $\mathrm{Ra}$ ). In some cases [1], sulphur $(\mathrm{S})$ can be used for selenium (Se). There is also justification for using other elemental analogues to the relevant radionuclides, although their applicability is dependent on the sampling conditions and on the modelling context.

\section{MATERIAL AND METHODS}

\subsection{Sites}

The sampling programme was carried out on $94,300 \mathrm{~m}^{2}$ permanent monitoring plots [2]. The plots were selected from the forest monitoring network, which comprises one plot per ha of forestry land, on the 
basis of the forest site type distribution and the tree stand characteristics measured on Olkiluoto during 2002-2004 [3-5].

\subsection{Sampling and element analyses}

On mineral soil sites three composite samples, each consisting of 10 sub-samples, were taken from the organic layer with a cylinder $(\mathrm{d}=60 \mathrm{~mm})$. Living vegetation was removed from the top of the subsample. Peat samples were collected at depths of $0-10 \mathrm{~cm}, 10-20 \mathrm{~cm}$ and $20-30 \mathrm{~cm}$ on the peatland sites. The fresh weight of the organic layer samples was determined, and the samples then air dried and weighed. The peat samples were dried at a temperature of $+60^{\circ} \mathrm{C}$. The peat and organic layer samples were milled to pass through a $2 \mathrm{~mm}$ bottom sieve.

Shoot (including leaves) samples of the most common or abundant evergreen and deciduous trees, dwarf shrub, herb, grass, bryophyte and lichen species were collected on each plot. Only the living, above-ground biomass was sampled. Current-year shoots of dwarf shrubs (evergreen species mainly Vaccinium vitis-idaea, and deciduous species Vaccinium myrtillus) were separated and the leaves were detached for chemical analysis. In the case of Calluna vulgaris and Lycopodium annotinum, the sample consisted of young shoots (stems and leaves). For small herbs (e.g. Maianthemum bifolium and Trientalis europaea) the sample consisted of the whole above-ground shoot, excluding inflorescences, whereas for tall herbs (Filipendula ulmaria, Rubus idaeus and Rubus saxatilis) only the leaves were sampled. The grass sample consisted of leaves and stems, excluding inflorescences. The bryophyte samples consisted of the three youngest annual segments $(\mathrm{C}, \mathrm{C}+1, \mathrm{C}+2)$. For reindeer lichens (Cladina) the upper, lightcoloured part was separated from the darker (decomposing) lower part for the sample. Leaf samples were collected from deciduous trees for chemical analysis at the end of growing season, and needle samples $(\mathrm{C}, \mathrm{C}+1)$ from conifer species during the dormant period.

The element concentrations were determined by microwave-assisted, wet digestion $\left(\mathrm{HNO}_{3} / \mathrm{H}_{2} \mathrm{O}_{2}\right)$ and analysed by ICP-AES. The results were expressed on a dry matter basis (determined by drying overnight at $+105^{\circ} \mathrm{C}$ ). The sampling, sample pre-treatment and analyses have been reported in more detail by Tamminen et al. [2].

\subsection{Concentration ratios}

Concentration ratios (CR) were calculated for $\mathrm{Al}, \mathrm{B}, \mathrm{Ca}, \mathrm{Cd}, \mathrm{Cr}, \mathrm{Cu}, \mathrm{Fe}, \mathrm{K}, \mathrm{Mg}, \mathrm{Mn}, \mathrm{Ni}, \mathrm{P}, \mathrm{S}$ and $\mathrm{Zn}$ by dividing the element concentration in the plant $\left(\mathrm{mg} \mathrm{kg}^{-1} \mathrm{~d}\right.$.w.) material with the corresponding concentration in the organic layer or uppermost $(0-10 \mathrm{~cm})$ peat layer $\left(\mathrm{mg} \mathrm{kg}^{-1} \mathrm{~d} . \mathrm{w}\right.$.). The CRs were grouped according to site fertility, tree stand age, dominant tree species and soil type (mineral soil and peatland). The plant material (needles, birch leaves, alder leaves, Vaccinium myrtillus and evergreen dwarf shrubs, mosses, herbs, grasses and lichens) was also divided into separate groups.

Since both the concentration in the soil and in plants is assumed to be normally distributed, the CR should follow a lognormal distribution. In order to test the potential differences between the different stand class and plant material groups, Bayesian hierarchical updating was applied, together with conventional fitting of a lognormal distribution, to the data. This was carried out using a test version (6 April 2008) of Babar software developed by Kristofer Stenberg et al. at Facilia AB (Stockholm, Sweden). As a priori distributions to be updated with the site data, data for the closest element or the overall variability over all the data for any element as given by Avila [6] were used. The use of more precise data would have required an extensive literature review outside the scope of this project. However, since the a priori distributions in most cases had huge variance, the resulting distribution updated by our site data was still dominated the broadly distributed literature data, and thus the difference analysis had to be based on conventional statistics. After finding appropriate groupings (see below), the final distributions of the site data were calculated by fitting a lognormal distribution using relevant parts of the EIKOS code [7], version 2.0 running on the Matlab version 2007a. Additional 

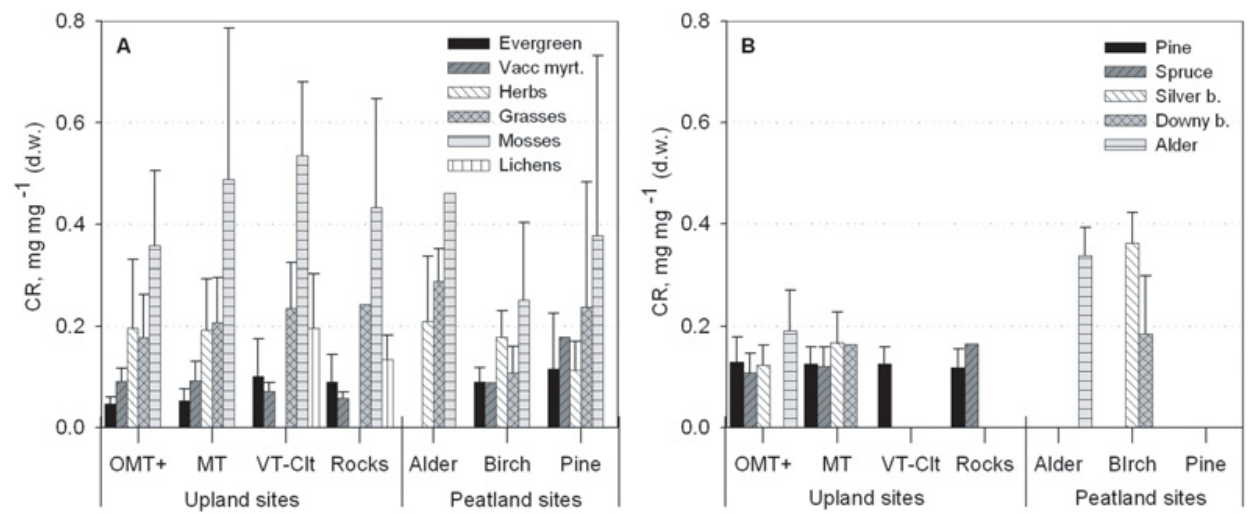

Figure 1. Site type specific CRs for $\mathrm{Ni}$ in the understorey vegetation in different plant groups (A) and tree foliage (B) at Olkiluoto. The forest site types [11] in descending order of site fertility: OMT $+=$ themostfertile, herb-rich sites and Oxalis acetosella-Vaccinium myrtillus types; $\mathrm{MT}=V$. myrtillus type; $\mathrm{VT}-\mathrm{ClT}=V$. vitis-idaea, Calluna vulgaris and Cladina types; Rocks = bedrock sites with no or very shallow mineral soil layer. Peatland sites were classified according to the dominant tree species. Tree species: Pine $=$ Pinus sylvestris, Spruce $=$ Picea abies, Silver birch $=$ Betula pendula, Downy birch $=$ B. pubescens, Alder $=$ Alnus glutinosa .

analysis of possible correlations between the CR and the stand age and the soil concentration was performed on Excel spreadsheets. The total number of individual CR values (plant-soil sample pairs) used to form different distribution combinations in the analysis was 5783 (1163 values for tree foliage, and 4620 for understorey vegetation).

\section{RESULTS AND DISCUSSION}

The CRs of Ni for the different groups of understorey plants and tree foliage are presented in Fig. 1 as an example of the grouping. The $\mathrm{CR}$ of $\mathrm{Ni}$ was higher in mosses than in other plants. The $\mathrm{CR}$ of $\mathrm{Ni}$ for tree foliage was also higher for deciduous trees on peatland sites than on mineral soil sites.

Overall, no significant differences were found between the different groupings for specific elements when the $95 \%$ confidence interval of the distributions was used. Different distributions for tree foliage are presented in Fig. 2 and for understorey plants in Fig. 3. At least some kind of relationship of the $\mathrm{CR}$ between the soil concentration and foliage was found for all elements except $\mathrm{Ni}$, and in many cases the relationship was nearly exponential. This is an interesting finding because the CR concept usually assumes none such relationship. No statistically significant correlations were found between the CR and stand age, but for some elements the variability within an age group appeared to be different. Statistically significant differences between the stand classes were found only for Al (young spruces on fertile sites had lower CRs than the other groups) and $\mathrm{Ni}$ (alder stands higher). The 50\% confidence interval indicated a number of differences between the groupings but their statistical significance was low.

On Olkiluoto, information is needed about the distribution of different key elements in forest ecosystems in order to carry out safety assessments where forests tend to dominate the dose to the most exposed persons using the landscape $[8,9]$. However, CR values can be obtained from site data using a wide range of approaches, not to mention generic literature. Before more detailed analyses of radionuclides are available, the non-radioactive elements utilized in this study will provide a sound basis for such analyses, especially because the data have been collected from the forests on Olkiluoto. Some issues, such as the fact that plants do not always take up nutrients and radionuclides in a similar manner, still need to be resolved in the application. For example, $\mathrm{K}$ is preferred by plants over Cs if $\mathrm{K}$ availability in the soil is good [e.g. 10]. Moreover, a distinction needs to be drawn between the input from airborne deposition and plant uptake via roots. Here, as in many other studies, the results are based 


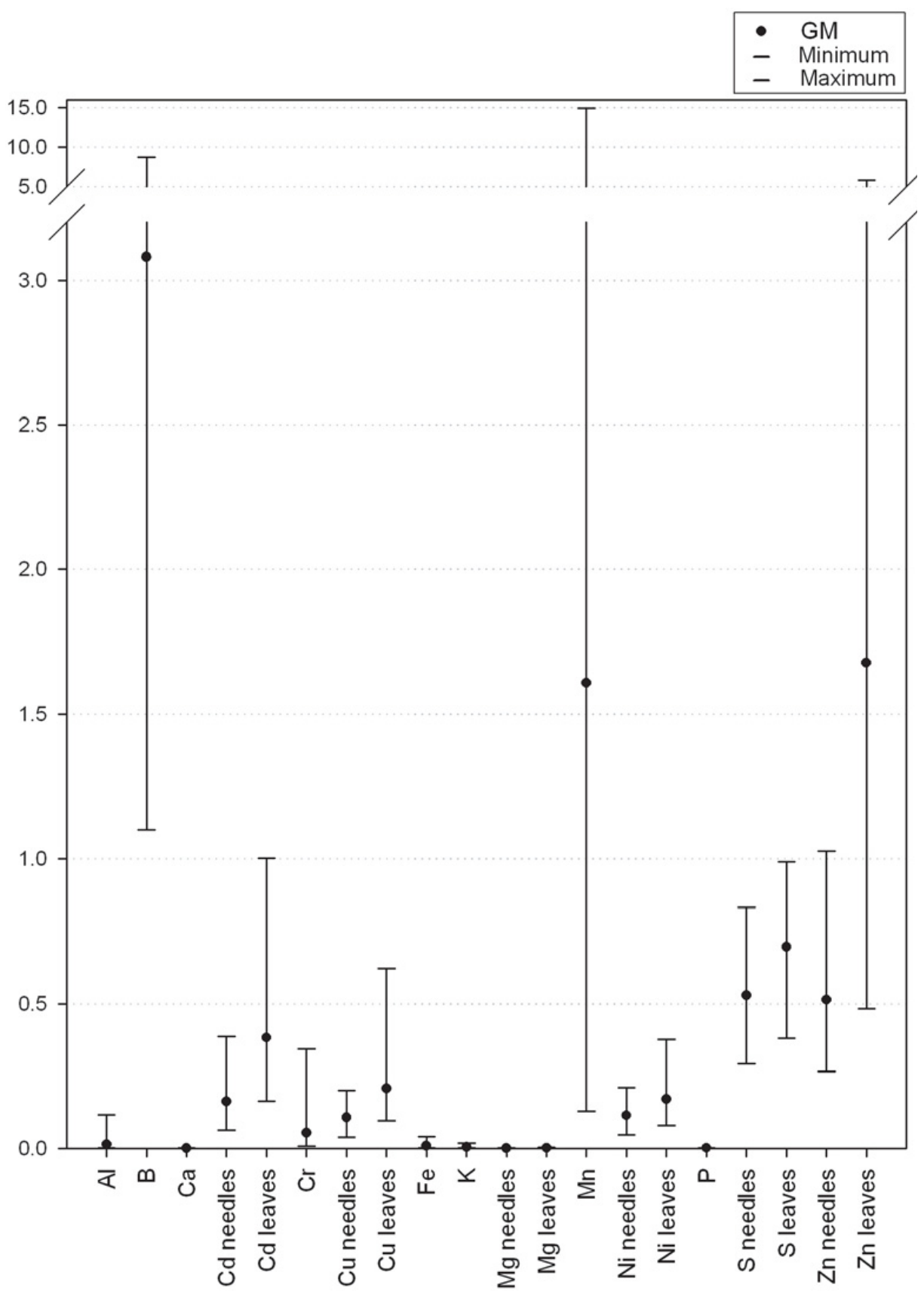

Figure 2. Distribution of concentration ratios (CR) in foliage for the studied elements. If only an element is denoted on the horizontal axis, the distribution includes all needle and leaf samples. Minimum and maximum refer to the lowest and highest values, whereas the geometric mean (GM) is the lognormal distribution fitted to the data.

only on element concentrations in the surface soil, and therefore part of the rooting zone of trees or other plants has been excluded. Data are available from deeper soil layers, but their applicability in this respect needs to be investigated because there is a decisive difference between the total concentrations and the bioavailable concentrations. 


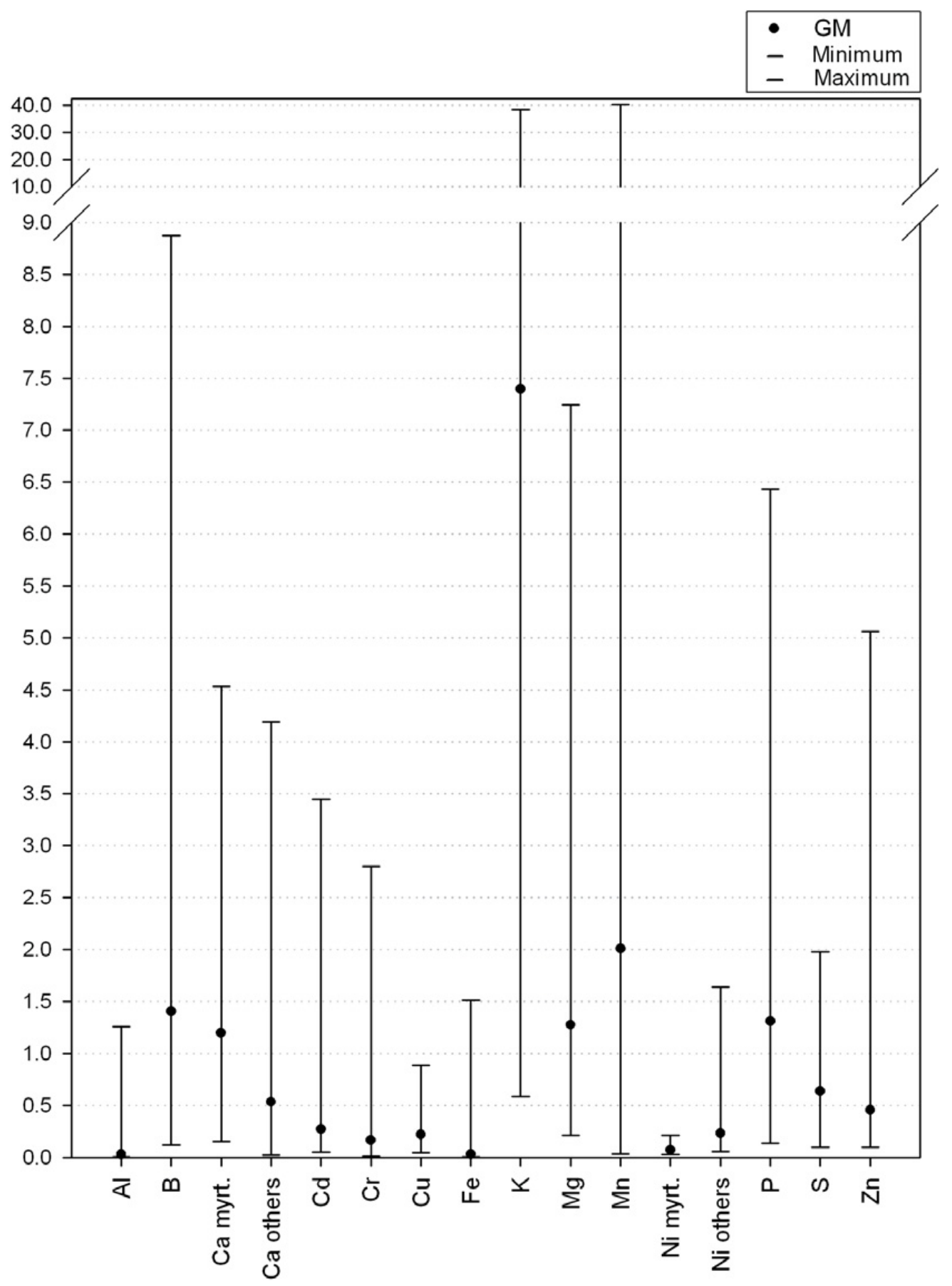

Figure 3. Distribution of concentration ratios $(\mathrm{CR})$ in understorey plants for the studied elements. If only an element is denoted on the horizontal axis, the distribution includes all plant group samples. Minimum and maximum refer to the lowest and highest values, whereas the geometric mean (GM) is the lognormal distribution fitted to the data. The group "myrt." consists of Vaccinium myrtillus and evergreen plants. 


\section{CONCLUSIONS}

On the basis of initial experiences with real site data for CRs in forest ecosystems at Olkiluoto, it appears that the current CR-based approach on radionuclide modelling in forest ecosystems is problematic due to the large variation in the parameter values and in their practical definition. A more mechanistic model would be preferred.

\section{References}

[1] de Souza M.P., Lytle C.M., Mulholland M.M., Otte M.L. and Terry N. Plant Physiology 122 (2000) 1281-1288.

[2] Tamminen P., Aro L. and Salemaa M. Posiva Working Report 78 (2007).

[3] Miettinen N. and Haapanen R. Posiva Working Report 54 (2002).

[4] Rautio P., Latvajärvi H., Jokela A. and Kangas-Korhonen P. Posiva Working Report 35 (2004).

[5] Saramäki J. and Korhonen K.T. Posiva Working Report 39 (2005).

[6] Avila R. SKB, Technical Report TR 06-08 (2006).

[7] Ekström P.-A. and Broed R. Posiva Working Report 31 (2006).

[8] Broed R. Posiva Working Report 108 (2007).

[9] Broed R., Avila R., Bergström U., Hjerpe T. and Ikonen A.T.K. Posiva Working Report 109 (2007).

[10] Kaunisto S., Aro L. and Rantavaara A. Environmental Pollution 117 (2002) 111-119.

[11] Cajander A.K. Acta Forestalia Fennica 56(5) (1949) 1-71. 